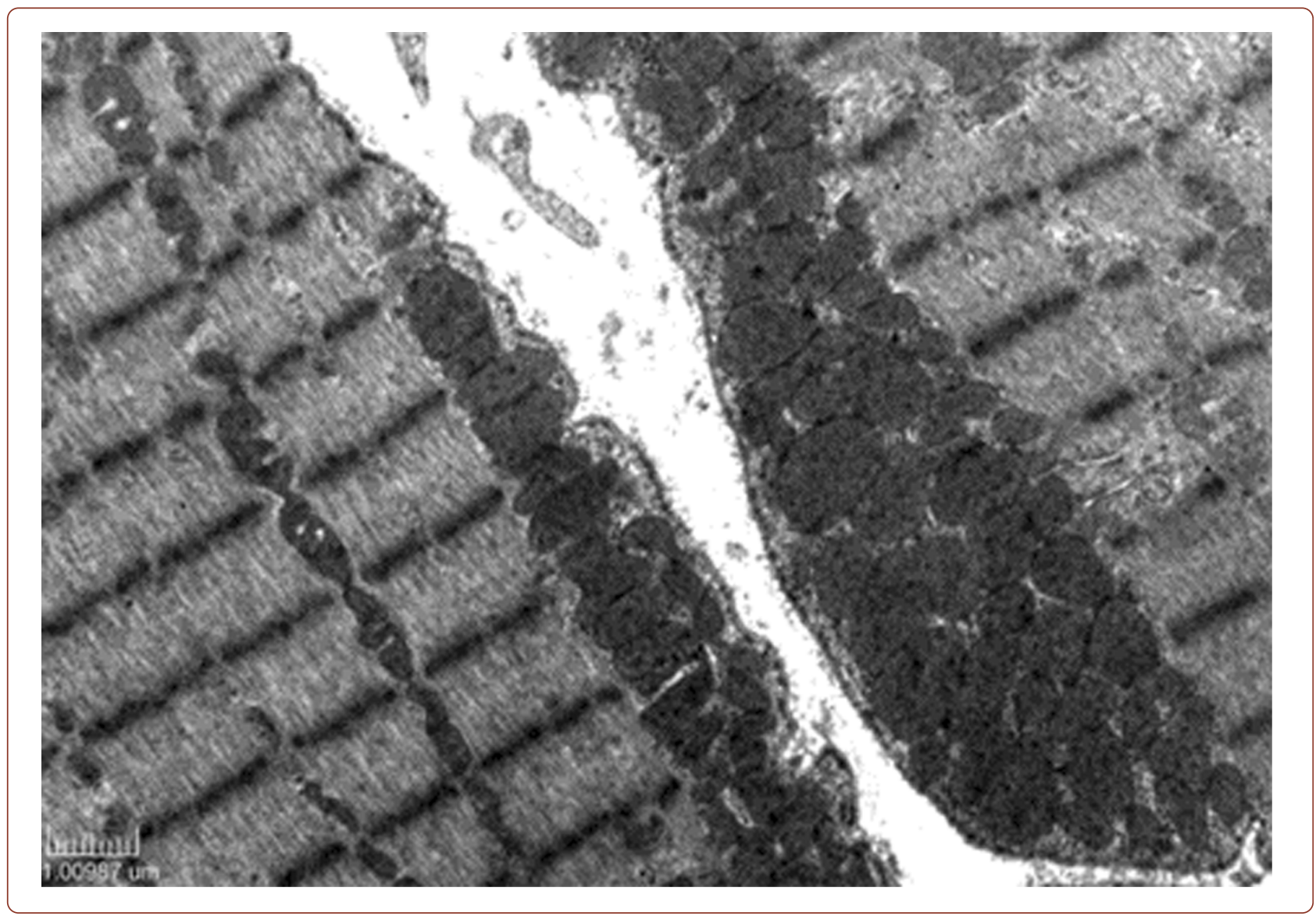

TWEAK promotes exercise intolerance by decreasing skeletal muscle oxidative phosphorylation capacity

Sato et al. 


\title{
TWEAK promotes exercise intolerance by decreasing skeletal muscle oxidative phosphorylation capacity
}

Shuichi Sato ${ }^{1}$, Yuji Ogura' ${ }^{1}$ Vivek Mishra ${ }^{1,3}$, Jonghyun Shin' ${ }^{1}$, Shephali Bhatnagar ${ }^{1}$, Bradford G Hill ${ }^{2}$ and Ashok Kumar ${ }^{1 *}$

\begin{abstract}
Background: Proinflammatory cytokine tumor necrosis factor (TNF)-like weak inducer of apoptosis (TWEAK) and its receptor Fn14 are the major regulators of skeletal muscle mass in many catabolic conditions. However, their role in muscle metabolism remains largely unknown. In the present study, we investigated the role of TWEAK on exercise capacity and skeletal muscle mitochondrial content and oxidative metabolism.
\end{abstract}

Methods: We employed wild-type and TWEAK-knockout (KO) mice and primary myotube cultures and performed biochemical, bioenergetics, and morphometric assays to evaluate the effects of TWEAK on exercise tolerance and muscle mitochondrial function and angiogenesis.

Results: TWEAK-KO mice showed improved exercise tolerance compared to wild-type mice. Electron microscopy analysis showed that the abundance of subsarcolemmal and intermyofibrillar mitochondria is significantly increased in skeletal muscle of TWEAK-KO mice compared to wild-type mice. Furthermore, age-related loss in skeletal muscle oxidative capacity was rescued in TWEAK-KO mice. Expression of a key transcriptional regulator peroxisome proliferator-activated receptor $y$ coactivator $1 \mathrm{a}(\mathrm{PGC}-1 \mathrm{a})$ and several other molecules involved in oxidative metabolism were significantly higher in skeletal muscle of TWEAK-KO mice. Moreover, treatment of primary myotubes with soluble TWEAK inhibited the expression of PGC-1a and mitochondrial genes and decreased mitochondrial respiratory capacity. Deletion of TWEAK also improved angiogenesis and transcript levels of vascular endothelial growth factor in skeletal muscle of mice.

Conclusions: These results demonstrate that TWEAK decreases mitochondrial content and oxidative phosphorylation and inhibits angiogenesis in skeletal muscle. Neutralization of TWEAK is a potential approach for improving exercise capacity and oxidative metabolism in skeletal muscle.

Keywords: Skeletal muscle, Exercise tolerance, TWEAK, Fn14, PGC-1a, PPARS

\section{Background}

Skeletal muscle is the largest tissue of the human body which ensures basic functions such as locomotion, metabolism, and respiration. Skeletal muscle exhibits a high level of plasticity in response to physiological stressors. For example, in response to exercise training, the proportion of slow-type fibers and mitochondrial content within fibers is noticeably increased [1]. The biogenesis

\footnotetext{
* Correspondence: ashok.kumar@louisville.edu

'Department of Anatomical Sciences and Neurobiology, University of Louisville School of Medicine, 500 South Preston Street, Louisville, KY 40202, USA Full list of author information is available at the end of the article
}

of new mitochondria and clearance of defunct mitochondria are essential to meet cellular energy demand especially during endurance exercise and to protect from many chronic conditions such as diabetes, heart failure, obesity, and aging $[2,3]$. Peroxisome proliferator-activated receptor (PPAR) $-\gamma$ coactivator $1 \alpha(\mathrm{PGC}-1 \alpha)$ is a key player in regulating skeletal muscle fiber composition, mitochondrial content, and oxidative metabolism, and maintenance of glucose, lipid, and energy homeostasis in response to physiological demands [4-6]. Transgenic mice overexpressing physiological levels of PGC- $1 \alpha$ in skeletal muscle have increased mitochondrial biogenesis and oxidative capacity,

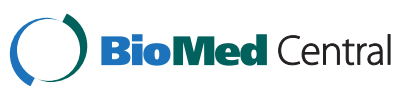


are more resistant to fatigue and have improved aerobic performance [7-10]. Forced expression of PGC-1 $\alpha$ also preserves skeletal muscle mass in various catabolic states including denervation [11,12]. PGC- $1 \alpha$ improves mitochondrial biogenesis by coactivating nuclear respiratory factor (NRF)-1 [13], NRF-2 [14] and estrogen-related receptor $\alpha$ [15-17] which, in turn, augments the expression of hundreds of nuclear-coded mitochondrial genes [18]. Recent evidence also suggests a role for mitochondria in preventing muscle protein degradation in catabolic conditions $[19,20]$. Thus, preserving mitochondria content and function is essential to countering muscle wasting and to improving muscle homeostasis.

Inflammatory cytokines such as tumor necrosis factor- $\alpha$ (TNF- $\alpha$ ) and interleukin-6 (IL-6) are some of the important mediators of loss of skeletal muscle mass and function in many catabolic conditions [21-24]. TNF- $\alpha$ has been reported to augment muscle protein degradation both in vitro and in vivo [25-27]. Moreover, TNF receptor I knockout (KO) mice are protected from diet-induced obesity due to increased thermogenesis [28]. Importantly, TNF- $\alpha$ inhibits the expression of PGC- $1 \alpha$ levels in myotubes [29]. In animal models of cancer cachexia, mitochondrial content and biogenesis are reduced with increased levels of IL-6 during the progression of the condition whereas inhibition of IL-6 activity attenuates tumor-induced loss of skeletal muscle [30,31]. It is also notable that while moderate exercise attenuates inflammation [32-34], acute exercise more robustly increases the levels of inflammatory cytokines in obese compared with lean subjects suggesting that rigorous exercise can further aggravate the condition of overweight individuals [35]. Despite these observations, cause-and-effect relationships between different inflammatory mediators, exercise tolerance, and mitochondrial function in skeletal muscle have not been clearly established using genetic mouse models.

TNF-like weak inducer of apoptosis (TWEAK) is a major proinflammatory cytokine of the TNF super family [36] that functions by binding to Fn14 receptors on target cells [37-39]. TWEAK-Fn14 signaling mediates unique and context-dependent pleiotropic effects [40]. TWEAK has been recently identified to be a key mediator that causes skeletal muscle loss that occurs in response to denervation, immobilization, and starvation [21,41,42]. Moreover, TWEAK-transgenic mice overexpressing physiological levels of TWEAK in skeletal muscle showed a higher proportion of fast-type fibers (glycolytic) in soleus and extensor digitorum longus (EDL) muscle [41] indicating that elevated levels of TWEAK cause a slowto-fast type fiber switch. However, the role and mechanisms by which TWEAK affects exercise capacity and bioenergetic function have not been studied.

In the present study, we have used TWEAK-knockout (KO) mice to investigate the role of TWEAK in exercise tolerance and skeletal muscle bioenergetic function. Our results show that, compared with wild-type mice, TWEAK-KO mice have increased exercise tolerance, which is associated with higher levels of skeletal muscle subsarcolemmal and intermyofibrillar mitochondria and enhanced oxidative phosphorylation capacity. TWEAK represses the expression of PGC- $1 \alpha$ and several other molecules involved in mitochondrial biogenesis and oxidative metabolism in vivo and in cultured myotubes. Furthermore, vascularization and expression of vascular endothelial growth factor (VEGF) are increased in skeletal muscle of TWEAK-KO mice compared with wildtype mice. These results support our hypothesis that TWEAK causes exercise intolerance by suppressing mitochondrial oxidative metabolism and angiogenesis.

\section{Methods}

\section{Cell culture}

Primary myoblasts were isolated from hind limb muscle of mice and cultured following the same protocol as previously described [43]. Briefly, hind limb skeletal muscles from mice were aseptically isolated, minced into a coarse slurry, and enzymatically digested at $37^{\circ} \mathrm{C}$ for one hour by adding $200 \mathrm{IU} / \mathrm{ml}$ collagenase I (cat \# LS004196; Worthington, Lakewood, NJ, USA) and $0.1 \%$ pronase (EMD Chemicals, Billerica, MA, USA). The digested slurry was filtered through a $70 \mu \mathrm{m}$ filter and spun, and isolated cells were resuspended and cultured initially in F-10 medium (containing 20\% fetal bovine serum (FBS) and supplemented with $10 \mathrm{ng} / \mathrm{ml}$ basic fibroblast growth factor) and then in F-10 plus (Dulbecco's) Modified Eagle's Medium ((D)MEM) (1:1 ratio) based culture medium supplemented with 15\% FBS on culture dishes coated with $10 \%$ matrigel (BD Biosciences, San Jose, CA, USA). Differentiation in primary myoblast cultures was induced by replacing the growth medium with differentiation medium ( $2 \%$ horse serum in (D)MEM).

\section{Animals}

TWEAK-KO mice were provided by Dr. Avi Ashkenazi (Genentech South, San Francisco, CA, USA) and have been previously described [40]. All the mice were in the C57BL/6 background, and their genotype was determined by PCR from tail DNA. All animal procedures were approved (protocol \# 10129) by the Institutional Animal Care and Use Committee and conformed to the American Physiological Society's Guiding Principles in the Care and Use of Animals.

\section{Treadmill running protocol}

Mice were subjected to treadmill running following the same previously described protocol [44]. In brief, 4.5-month-old wild-type and TWEAK-KO mice were matched for body weight and randomly assigned to 
either a sedentary or exercise group. Mice were subjected to an acute bout of treadmill (Eco3/6 treadmill; Columbus Instruments, Columbus, OH, USA) running at $15 \mathrm{~m} /$ minute for 90 minutes. All mice in the exercise group finished the 90-minute trial and were visibly exhausted. Mice were sacrificed within 30 minutes after exercise to study mitochondrial function.

\section{Exercise tolerance test}

The exercise tolerance test on mice was performed following a method as previously described [45]. Briefly, all animals were run on a treadmill (Columbus Instruments) at $10 \mathrm{~m} /$ minutes for five minutes at $0 \%$ degree incline for acclimation for three days. On the exercise testing day, animals ran on the treadmill with a fixed slope of $10 \%$. Mice first ran at $10 \mathrm{~m} /$ minute for five minutes and the speed was increased by $2 \mathrm{~m} /$ minute every two minutes until they were exhausted or a maximal speed of $46 \mathrm{~m} /$ minute was achieved. The criterion of exhaustion was defined as the inability of the animal to run on the treadmill for 10 seconds despite mechanical prodding. Running time and maximum speed achieved was measured whereas running distance, work and power were calculated.

\section{Transmission electron microscopy}

Soleus muscles from wild-type and TWEAK-KO mice were fixed in $3 \%$ glutaraldehyde in $0.1 \mathrm{M}$ cocodylate buffer overnight followed by fixing in $1 \%$ cocodylatebuffered osmium tetroxide. The tissue was dehydrated through a series of graded alcohols, and embedded in LX-112 plastic (Ladd Research Industries, Williston, VT, USA). Longitudinal sections $(80 \mathrm{~nm})$ were cut using an ultramicrotome (LKB, Rockville, MD, USA)) and stained with uranium acetate and lead citrate. Samples were analyzed using a transmission electron microscope (Philips CM 12; HZB, Berlin, Germany) operating at $60 \mathrm{kV}$. The pictures were captured at 8,800x magnification using a 3.2 megapixel digital camera (Sia-7C; Kodak, Rochester, NY, USA) at room temperature. No imaging medium was used to visualize the pictures, and images were stored as JPEG files. Image levels were equally adjusted using Photoshop CS2 software.

\section{Succinate dehydrogenase (SDH) staining}

SDH staining was performed as previously described [46]. Briefly, transverse sections $(8 \mu \mathrm{m})$ were cut from the mid-belly of the TA muscles on a cryostat at $-20^{\circ} \mathrm{C}$ and stored at $-80^{\circ} \mathrm{C}$ until SDH staining was performed. The sections were dried at room temperature for $30 \mathrm{mi}-$ nutes before incubation in a solution made up of $0.2 \mathrm{M}$ phosphate buffer ( $\mathrm{pH} 7.4$ ), $0.1 \mathrm{M} \mathrm{MgCl}_{2}, 0.2 \mathrm{M}$ succinic acid (Sigma Chemical Company, St. Louis, MO, USA) and $2.4 \mathrm{mM}$ nitroblue tetrazolium (NBT, Sigma) at $37^{\circ} \mathrm{C}$ in a humidity chamber for 45 minutes. The sections were then washed in deionized water for three minutes, dehydrated in $50 \%$ ethanol for two minutes, and mounted for viewing with DPX mount medium (Electron Microscopy Sciences, Hatfield, PA, USA). Digital photographs were taken from each section at 10X magnification under a Nikon Eclipse TE 2000-U microscope (Nikon, Melville, NY, USA) with a Nikon digital camera (Digital Sight DSFi1), and fibers were quantified with imaging software (Image J, NIH). At least 700 fibers were counted to determine SDH-positive fibers in each section in a blinded fashion. The percentage of SDH stained fibers was then determined based on a criteria using integrated optical density.

\section{Measurement of mitochondrial bioenergetics}

Mitochondrial oxidative capacity was measured in isolated mitochondria and in cultured myotubes using a Seahorse Bioscience XF24 extracellular flux analyzer (Billerica, MA, USA). For measurements in isolated mitochondria, tissue from the limb muscle (approximately $50 \mathrm{mg}$ ) was isolated within 30 minutes of exercise and homogenized in $1 \mathrm{ml}$ of isolation buffer $(220 \mathrm{mM}$ mannitol, $70 \mathrm{mM}$ sucrose, $5 \mathrm{mM}$ 3-(N-morpholino)propanesulfonic acid (MOPS), $1 \mathrm{mM}$ ethylene glycol tetraacetic acid (EGTA), 0.3\% fatty acid-free BSA, pH 7.2) using a Potter Elvehjem tube and a Teflon pestle. The homogenate was centrifuged at $500 \times \mathrm{g}$ for five minutes at $4^{\circ} \mathrm{C}$. The supernatant containing mitochondria was centrifuged at $10,000 \times \mathrm{g}$ for five minutes. After two wash-centrifugation steps in BSA-free isolation buffer, the mitochondria were suspended in respiration buffer (120 mM KCl, $25 \mathrm{mM}$ sucrose, $10 \mathrm{mM}$ 4-(2-hydroxyethyl)1-piperazineethanesulfonic acid (HEPES), $1 \mathrm{mM} \mathrm{MgCl}_{2}, 5$ $\mathrm{mM} \mathrm{KH}_{2} \mathrm{PO}_{4}$, $\mathrm{pH}$ to 7.2). Protein in the mitochondrial suspension was estimated using the Lowry DC assay (Biorad, Hercules, CA, USA) and 5 to $12.5 \mu \mathrm{g}$ of mitochondrial protein was sedimented in XF culture plates as described previously [47]. Complex I-mediated, state 3 respiratory activity was determined by measuring the oxygen consumption rate (OCR) after injection of pyruvate $(5 \mathrm{mM})$, malate $(2.5 \mathrm{mM})$ and ADP $(1 \mathrm{mM})$. The OCR of mitochondria after exposure to oligomycin $(1 \mu \mathrm{g} / \mathrm{ml})$ was used to estimate state 4 activity; exposure to carbonyl cyanide $p$-trifluoromethoxyphe nylhydrazone (FCCP, $2 \mu \mathrm{M}$ ) was used to examine the uncoupled rate of respiration. Finally, succinate $(10 \mathrm{mM})$ and rotenone $(1 \mu \mathrm{M})$ were injected to assess maximal Complex II-mediated respiratory capacity. Data are expressed as pmol $\mathrm{O}_{2} / \mathrm{min} / \mu \mathrm{g}$ protein. For measurements in cultured cells, differentiated myoblasts were exposed to soluble TWEAK (R\&D Systems, Minneapolis, MN, USA) for 72 hours followed by the mitochondrial function assay outlined previously [48-51]. 


\section{RNA isolation and quantitative real time-PCR}

RNA isolation and quantitative real time-PCR (qRT-PCR) were performed as previously described [41]. Briefly, total RNA was isolated from homogenized mouse tissues using the TRIzol reagent (Invitrogen, Grand Island, NY, USA) and an RNeasy Mini kit (QIAGEN, Valencia, CA, USA) according to the manufacturers' protocols. First strand cDNA for PCR analyses were made using a reverse transcription system with $1 \mu \mathrm{g}$ of purified RNA using oligo (dT) primer (Applied Biosystems, Grand Island, NY, USA) and the Omniscript reverse transcription kit (QIAGEN). The quantification of mRNA expression was performed using the SYBR green dye method on a sequence detection system (Applied Biosystems, model 7300). Primers were designed using Vector NTI software (Invitrogen). Primer sequences are available on request. The thermal conditions consisted of an initial denaturation at $95^{\circ} \mathrm{C}$ for 10 minutes, followed by 40 cycles of denaturation at $95^{\circ} \mathrm{C}$ for 15 seconds, annealing and extension at $60^{\circ} \mathrm{C}$ for one minute, and, for a final step, a melting curve of $95^{\circ} \mathrm{C}$ for 15 seconds, $60^{\circ} \mathrm{C}$ for 15 seconds, and $95^{\circ} \mathrm{C}$ for 15 seconds. All reactions were performed in duplicate to reduce variation. Data normalization was accomplished using the endogenous control ( $\beta$-actin), and the normalized values were subjected to a $2^{-\Delta \Delta C t}$ formula to calculate the fold change between control and experimental groups.

\section{Immunostaining for CD31}

After cutting $8 \mu \mathrm{m}$ thickness frozen sections of TA muscles, the sections were fixed by cold acetone for 10 minutes and dried in air for 30 minutes. The tissues were rinsed with phosphate buffered saline (PBS) twice, blocked in $2 \%$ BSA solution for one hour at room temperature followed by incubation with primary antibodies in 2\% BSA solution (laminin, anti-rabbit 1:300, Sigma and CD31, anti-mouse 1:30, BD Biosciences, San Jose, CA, USA) at $4^{\circ} \mathrm{C}$ in a humidity chamber overnight. The next day, the sections were rinsed with PBS for five minutes three times and incubated with secondary antibody (Alexa Fluor-conjugated 488 anti-rabbit, 1:2500 and 546 anti-mouse, 1:2500, Invitrogen) in $2 \%$ BSA solution for one hour at room temperature. After washing twice with PBS and once with deionized water, the sections were mounted with DPX mounting medium. Digital photographs were taken from each section under a Nikon Eclipse TE 2000-U microscope (Nikon) with a Nikon digital camera (Digital Sight DS-Fi1). Number of CD31-postive vessels per myofiber was quantified using NIS Elements BR 3.00 software (Nikon).

\section{Statistical analysis}

The results are presented as means \pm standard deviation (SD). Student's $t$-test was used to compare the difference between control and treatment groups. A value $P<0.05$ was considered statistically significant.

\section{Results}

Improvement in exercise tolerance in TWEAK-KO mice

We first studied the role of TWEAK in exercise tolerance in mice. Male 4.5-month old wild-type and TWEAK-KO mice were acclimated for three days for treadmill running prior to the exercise tolerance test. After acclimation, the mice were run on a $10 \%$ slope until the mice were unable to run on the treadmill for 10 seconds despite mechanical prodding. TWEAK-KO mice ran longer compared to wild-type mice $(1,483$ seconds for TWEAK-KOs versus 1,170 seconds for the controls, Figure $1 \mathrm{~A})$. Since TWEAKKO mice could keep running on higher speed $(30.6 \mathrm{~m} /$ minute for TWEAK-KOs versus $25.5 \mathrm{~m} /$ minute for the controls, Figure 1B), the difference in running distance became greater than $47 \%$ (463 meter for TWEAK-KOs versus 314 meter for the controls, Figure 1C). Work and power generated by TWEAK-KO mice were also higher compared to wild-type mice. TWEAK-KO mice generated $22.2 \mathrm{~J}$ of work while control mice generated $15.2 \mathrm{~J}$ of work (a difference of 46\%) during the exercise test (Figure 1D). In turn, TWEAK-KO mice exerted $14 \%$ more power than the controls $(14.9 \mathrm{~mW}$ for TWEAK-KO versus $13.0 \mathrm{~mW}$ for the wild-type, Figure 1E) on the treadmill. These data established that TWEAK-KO mice have significantly improved exercise tolerance.

\section{Ablation of TWEAK improves mitochondrial content in skeletal muscle of mice}

We have previously shown that deletion of TWEAK increases the proportion of type I fibers in soleus and EDL muscles of mice [41]. In this study, we investigated whether TWEAK affects mitochondrial content in skeletal muscle of mice. The soleus muscle of 4.5-month old TWEAK-KO and wild-type mice were isolated and used to measure mitochondrial content by performing transmission electron microscopy. As shown in Figure 2A, the abundance and size of mitochondria was found to be increased in TWEAK-KO compared to wild-type mice. Quantitative analysis of mitochondria in electron micrographs showed that the levels of subsarcolemmal and intermyofibrillar mitochondria were increased by $42 \%$ and $32 \%$, respectively, in TWEAK-KO mice compared to wild-type mice (Figure 2B and Figure 2C). Because gastrocnemius (GA) muscle contains a mixture of slow and fast twitch fibers and greatly influences running capacity on the treadmill, we measured mRNA levels of fiber typespecific myosin heavy chain (MyHC) isoforms in GA muscle of wild-type and TWEAK-KO mice. As shown in Figure 2D, mRNA levels of MyHC I and MyHC IIA were increased by 2 - and 2.7-fold, respectively in TWEAK-KO mice compared to wild-type mice. These results further 
A.

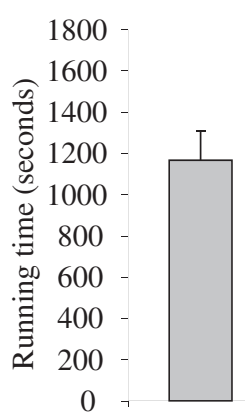

D.

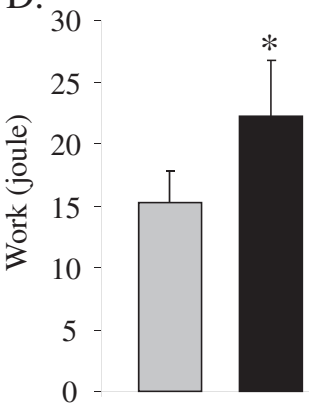

B.

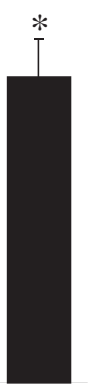

$$
\text { 仓ั }
$$

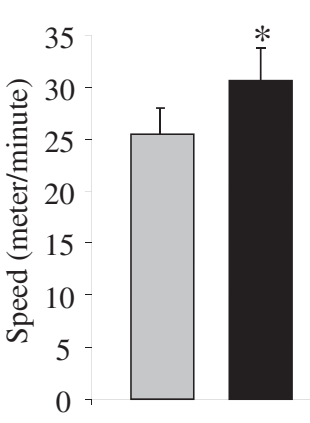

E. 18

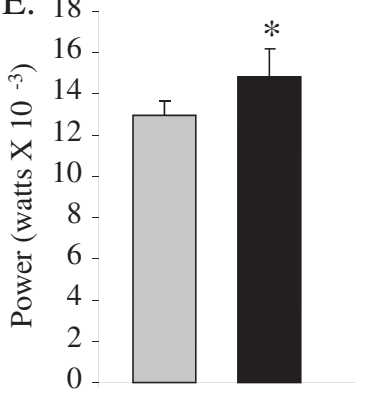

C.

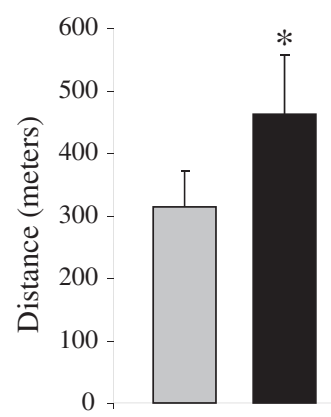

Figure 1 Treadmill exercise tolerance test. After acclimatization, mice were run on a treadmill with a 10\% slope and increasing speed to exhaustion. Maximum speed and running time were monitored, and distance, work, and power were calculated based on the individual performance. (A) Running time; (B) Speed; (C) Distance; (D) Work; and (E) Power. Data are represented as mean \pm SD. $\mathrm{N}=6$ in each group. ${ }^{*} P<0.05$; values vary significantly between wild-type and TWEAK-KO mice. KO, knockout.

suggest that genetic ablation of TWEAK increases the slow-type fiber phenotype in skeletal muscle of mice.

$\mathrm{SDH}$, also known as complex II in the mitochondrial respiratory chain, is a marker of oxidative capacity of skeletal muscle at the fiber level. Therefore, we performed SDH staining on TA muscle of 4.5-month- and 12-monthold wild-type mice and TWEAK-KO mice and quantified the percentage of SDH-positive fibers. Compared to wildtype mice, fibers in TWEAK-KO mice stained more darkly for SDH (Figure 3A). Furthermore, there was a significant increase in the number of SDH-positive fibers in TWEAK$\mathrm{KO}$ mice compared to wild-type mice at the age of 4.5 months (Figure 3B). Likewise, 12-month-old TWEAK-KO had more SDH-positive fibers compared to age-matched wild-type mice (Figure 3A and Figure 3C). Taken together, these results suggest that ablation of TWEAK in mice is sufficient to improve mitochondrial content and oxidative capacity of skeletal muscle.

\section{TWEAK-KO mice demonstrate increased expression of} PGC-1 $a$ and metabolic genes in skeletal muscle

To understand the mechanisms by which TWEAK affects exercise capacity and mitochondrial content in skeletal muscle, we investigated whether TWEAK modulates the expression of PGC-1 $\alpha$, a critical regulator of the mitochondrial biogenetic program in skeletal muscle $[9,10]$. Interestingly, the mRNA levels of PGC- $1 \alpha$ were found to be significantly higher in 4.5-month-old TWEAK-KO mice compared to age-matched wild-type mice (Figure 4). Similarly, mRNA levels of PPAR $\delta$ were significantly higher in skeletal muscle of TWEAK-KO mice compared to corresponding wild-type mice (Figure 4). In contrast, mRNA levels of glycolytic enzymes such as hexokinase-2 (HK II) and phosphoglycerate mutase 2 (PGAM2) were reduced in skeletal muscle of TWEAK-KO mice compared to wildtype mice. No significant change was observed in the expression of pyruvate dehydrogenase kinase-4 (PDK4). Furthermore, mRNA levels of mitochondrial carnitine palmitoyltransferase I (mCPT1), which is required for the transport of long-chain fatty acyl-CoAs from the cytoplasm into the mitochondrion, were significantly elevated in TWEAK-KO mice compared to wild-type mice (Figure 4). These results suggest that a deficiency of TWEAK reduces expression of glycolytic genes and augments the expression of genes involved in oxidative metabolism in skeletal muscle. 

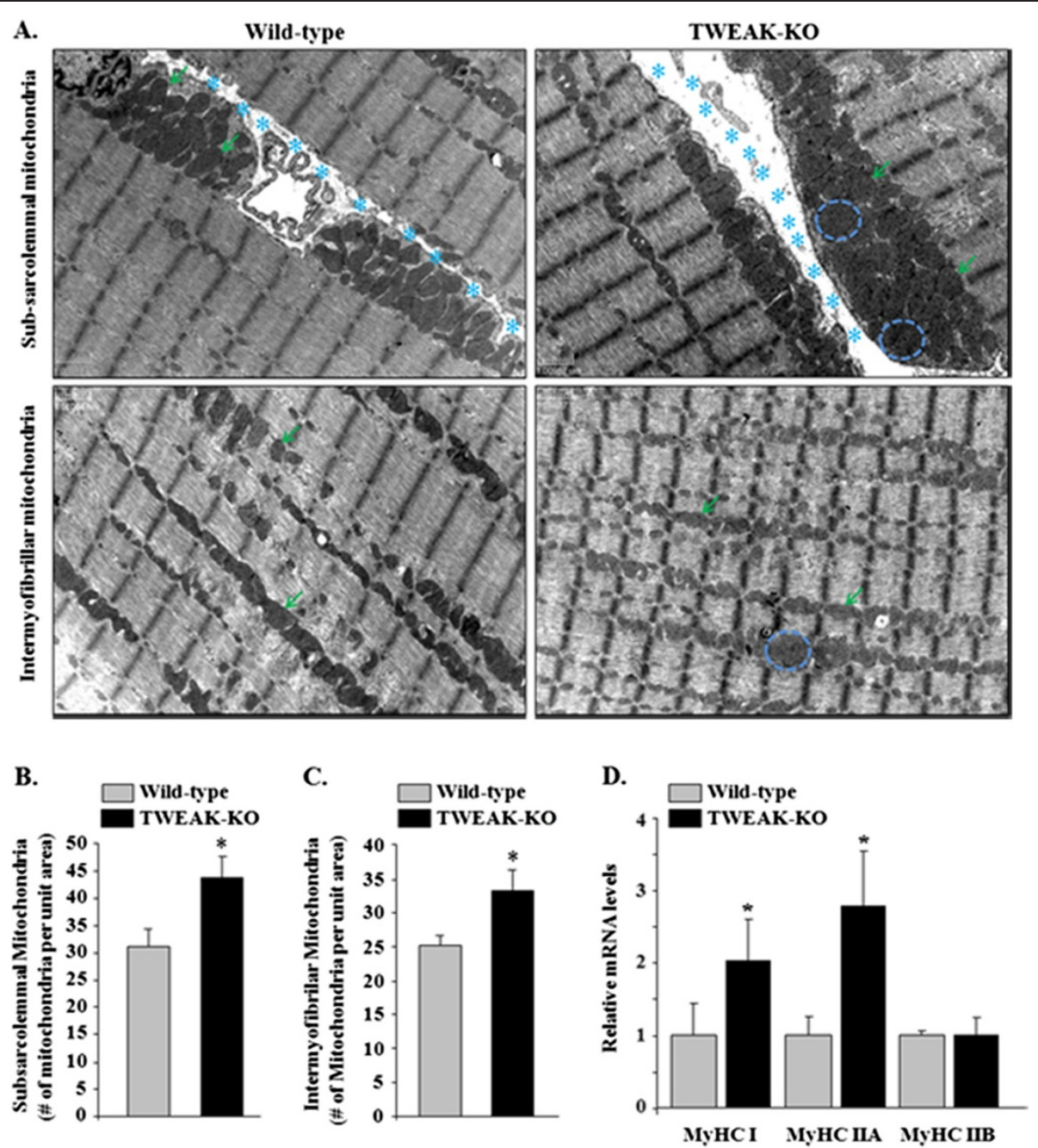

Figure 2 Transmission electron microscopy (TEM) analysis for mitochondria morphology and content and expression of muscle fiber type-specific genes in TWEAK-KO mice. Soleus muscle of six-month-old wild-type and TWEAK-KO mice were isolated and longitudinal sections were processed for TEM analysis. (A) Representative images of longitudinal soleus muscle are shown. The abundance and the size of mitochondria were increased in TWEAK-KO mice compared to wild-type mice. Arrows point to mitochondria in muscle sections. Circles are used to show

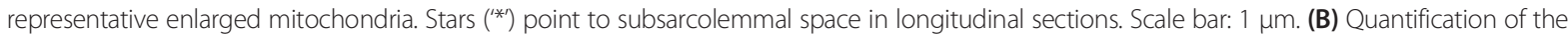
number of subsarcolemmal mitochondria in soleus muscle of wild-type and TWEAK-KO mice. (C) Quantification of the number of intermyofibrillar mitochondria in soleus muscle sections of wild-type and TWEAK-KO mice. (D) Relative mRNA levels of MyHC type I, IIA and IIB in gastrocnemius muscle of 4.5-month-old wild-type and TWEAK-KO mice. Data are represented as mean \pm SD. $N=3$ in each group. * $P<0.05$; values vary significantly from wild-type mice. KO, knockout; TWEAK, TNF-like weak inducer of apoptosis.

\section{Ablation of TWEAK increases state 3 respiration in skeletal muscle mitochondria}

We next sought to determine whether TWEAK regulates mitochondrial function in skeletal muscle. After an acute bout of treadmill running for 90 minutes, mitochondria were isolated from hind limb muscles of wild type and TWEAK-KO mice and mitochondrial function was examined by extracellular flux (XF) analysis. The sequential addition of respiratory substrates and inhibitors of oxidative phosphorylation were used to determine changes in electron transport chain activity: state 3 respiration was induced by addition of pyruvate, malate and ADP; state 4 respiration was induced by addition of oligomycin; FCCP was added to determine maximal complex I-mediated respiratory activity; and, lastly, succinate and rotenone were added to determine maximal complex II-mediated respiratory activity. As shown in Figure 5A and 5B, mitochondria from TWEAK-KO mice showed significantly increased state 3 respiratory activities compared with wild type mice. Mitochondrial coupling (as determined by calculating respiratory control ratios) and other indices of mitochondrial function were not significantly different 


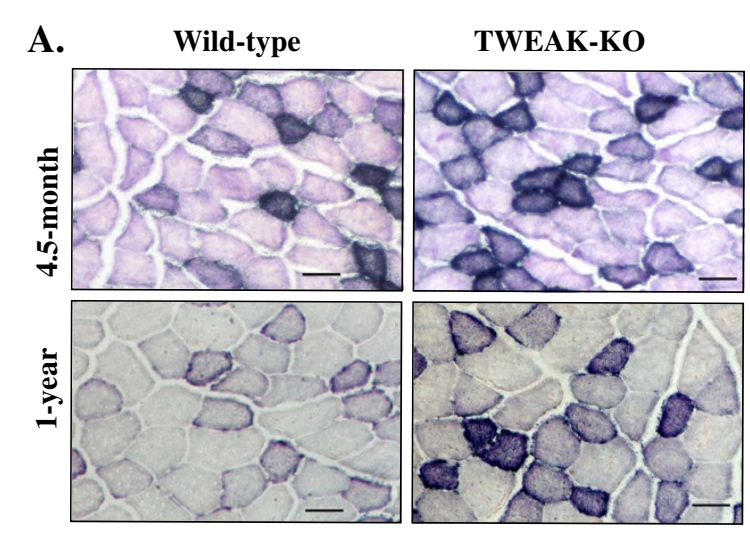

B.

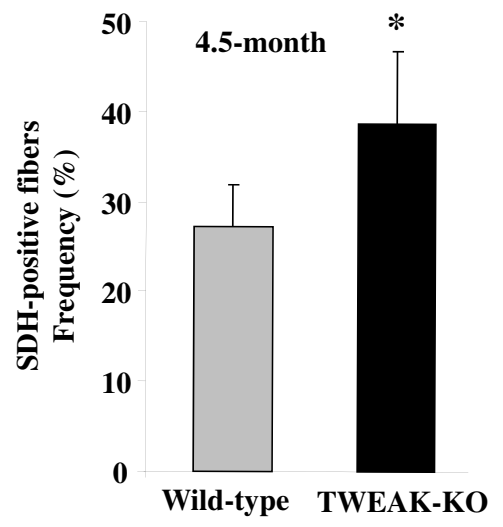

C.

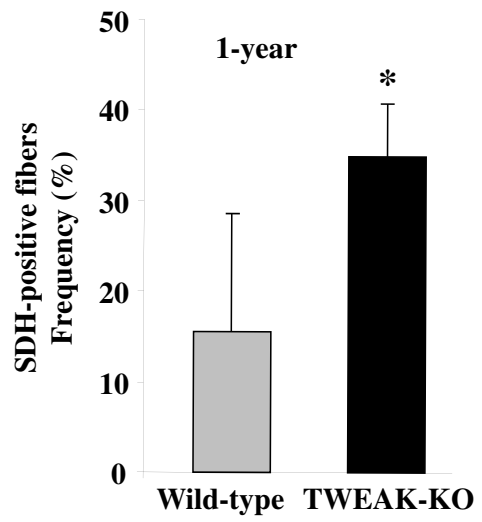

Figure 3 Succinate dehydrogenase (SDH) staining analysis for oxidative capacity in TA muscle of TWEAK-KO mice. Frozen transverse TA muscle sections from 4.5- or 12-month old wild-type and TWEAK-KO mice were used to stain for SDH. (A) Representative SDH-stained images are presented here. TA muscle of TWEAK-KO showed relatively dark staining for SDH compared to wild-type mice. Scale bars: 50 um. Quantification of SDH-positive fibers in TA muscle of (B) 4.5-month, and (C) 12-month old wild-type and TWEAK-KO mice. Data are presented as mean \pm SD. * $P<0.05$; values vary significantly from wild-type mice. KO, knockout; TA, tibial anterior; TWEAK, TNF-like weak inducer of apoptosis.

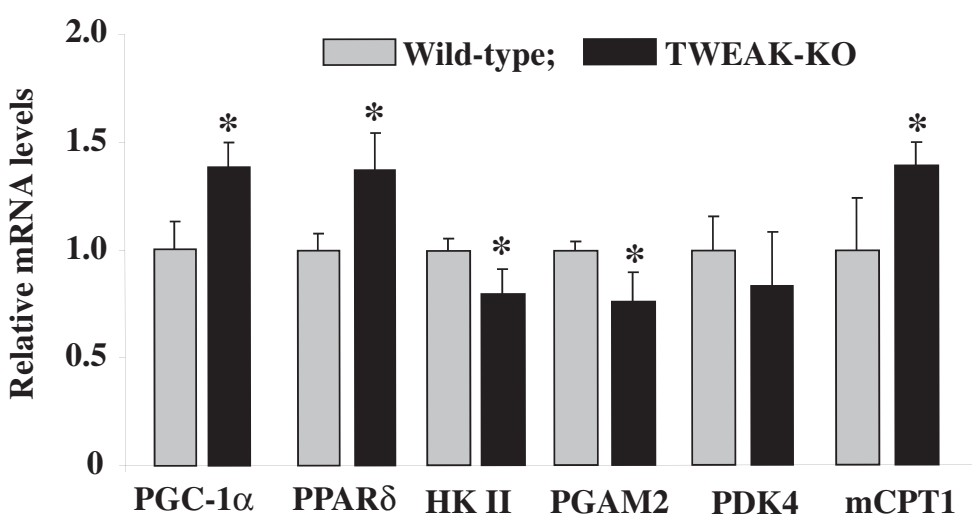

Figure 4 qRT-PCR analysis of transcript levels of metabolic genes in skeletal muscle of wild-type and TWEAK-KO mice. TA muscle from 4.5-month-old wild-type and TWEAK-KO mice were isolated and processed to measure mRNA levels of PGC-1a, PPARS, HK II, PGAM2, PDK4, and mCPT1. Data are represented as mean \pm SD. $N=4$ in each group. ${ }^{*} P<0.05$. values vary significantly from wild-type mice. HK II, hexokinase-2; KO, knockout; $\mathrm{mCPT1}$, mitochondrial carnitine palmitoyltransferase 1; PDK4, pyruvate dehydrogenase kinase-4; PGAM2, phosphoglycerate mutase 2; PGC-1a, PPAR coactivator 1a; PPAR, peroxisome proliferator-activated receptor; TA, tibial anterior; TWEAK, TNF-like weak inducer of apoptosis. 


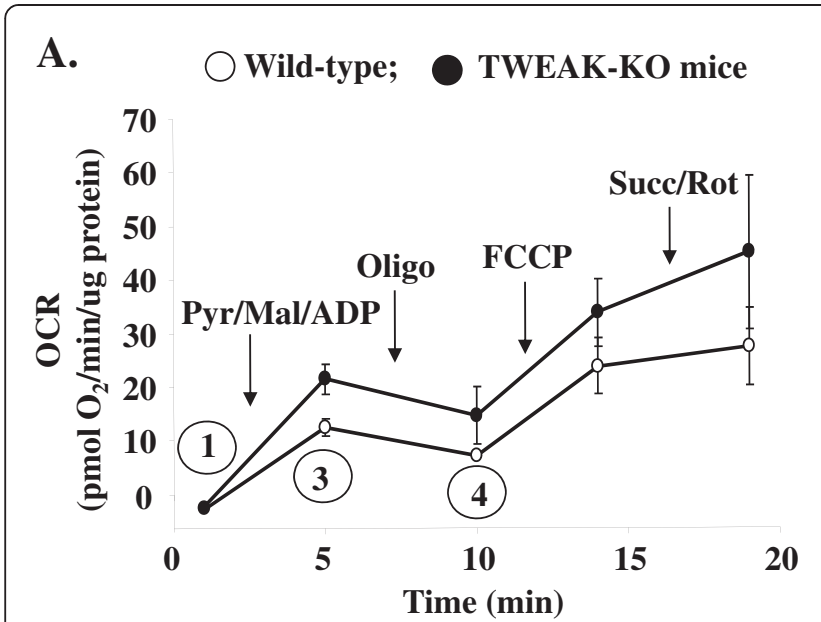

B.

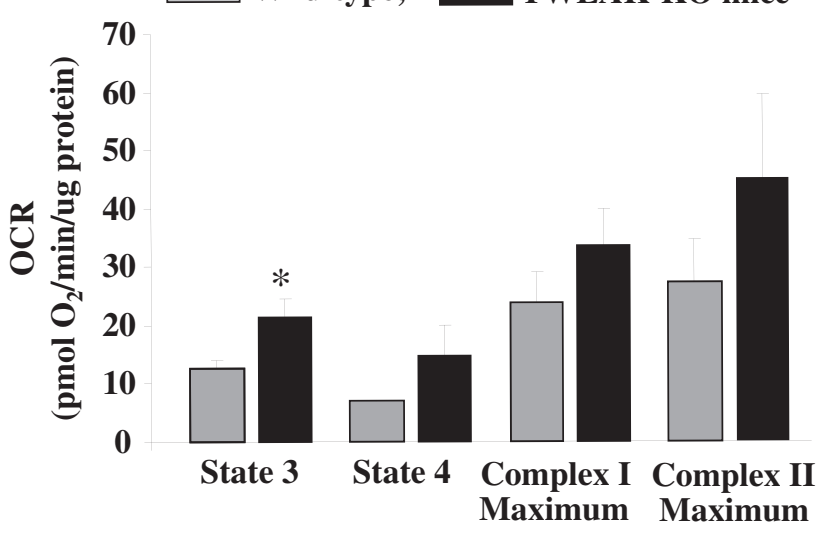

Figure 5 Mitochondrial respiration is enhanced in TWEAK-KO mice. Respiratory activity of mitochondria isolated from wild-type and TWEAK-KO mice subjected to an acute bout of treadmill running: (A) Extracellular flux assay of isolated mitochondria: mitochondrial activity was measured in the absence of substrate (state 1 respiration) or in the presence of pyruvate (5 mM), malate (2.5 mM) and ADP (1 mM) (state 3 respiration). State 4 respiration was estimated by measuring the oxygen consumption rate (OCR) after the addition of oligomycin ( $1 \mu \mathrm{g} / \mathrm{ml})$. FCCP $(4 \mu \mathrm{M})$ was added to assess maximal activity of mitochondria respiring on substrates providing electrons for complex I (that is, pyruvate and malate) or complex II (that is, succinate in the presence of rotenone; $10 \mathrm{mM}$ and $1 \mu \mathrm{M}$, respectively). (B) Group data derived from panel A. $\mathrm{N}=3$ mice per group. ${ }^{*} P<0.05$ versus wild-type. FCCP, carbonyl cyanide $p$-trifluoromethoxyphenylhydrazone; KO, knockout; TWEAK, TNF-like weak inducer of apoptosis.

between wild type and $\mathrm{KO}$ mice. These data suggest that absence of TWEAK augments mitochondrial oxidative capacity in skeletal muscle in exercised mice.

TWEAK represses the expression of PGC-1a and genes regulating oxidative metabolism in cultured primary myotubes

We next studied whether TWEAK affects the expression of PGC- $1 \alpha$ and other genes in cultured primary myotubes. Primary myoblasts prepared from wild-type mice were differentiated into myotubes by incubation in differentiation medium for 96 hours followed by treatment with TWEAK for 72 hours. As shown in Figure 6, addition of soluble TWEAK dramatically reduced the expression of PGC- $1 \alpha$ in myotubes. Treatment with TWEAK also significantly reduced the mRNA levels of several mitochondrial genes encoding proteins related to oxidative metabolism, such as ATP synthase subunit beta (ATP5b), cytochrome c oxidase subunit I (Cox I), Cox subunit IV (COX IV), COX 7b, cytochrome c (Cyt c), medium-chain acyl-coenzyme A dehydrogenase (MCAD), PPAR $\delta$, and MCPT1 (Figure 6). These results further suggest that TWEAK inhibits the mitochondrial biogenetic program in skeletal muscle.

TWEAK decreases maximal respiratory capacity and increases glycolysis in cultured primary myotubes Our studies in isolated mitochondria derived from skeletal muscle after exercise suggest that the absence of TWEAK increases mitochondrial oxidative capacity. To assess the effects of TWEAK on mitochondrial function directly, we exposed differentiated myotubes to TWEAK and then assessed mitochondrial function as described previously [48-51]. As shown in Figure 7A and 7B, exposure of myotubes to TWEAK for 72 hours did not affect the basal mitochondrial OCR, nor did it affect ATP-linked OCR or proton leak. However, the FCCPstimulated OCR, indicative of maximal respiratory capacity, was remarkably diminished by TWEAK treatment. In addition, a modest, yet significant, increase in the non-mitochondrial OCR occurred in myotubes exposed to100 ng/ml TWEAK, which may be due to increased production of reactive oxygen species. The diminishment in mitochondrial respiratory capacity caused by TWEAK was associated with an increase in the extracellular acidification rate (ECAR), a surrogate measure of glycolysis (Figure 7C). Collectively, these results suggest that TWEAK directly modulates the bioenergetic capacity of skeletal muscle.

\section{Ablation of TWEAK improves angiogenesis in skeletal muscle of mice}

There is a causal relationship between PGC-1 $\alpha$ and angiogenesis. Skeletal muscle-specific overexpression of PGC- $1 \alpha$ in mice results in increased angiogenesis, which may contribute to enhanced exercise performance [52]. Since TWEAK suppresses PGC- $\alpha$ in skeletal muscle, we next sought to determine whether TWEAK also regulates angiogenesis in skeletal muscle of mice. TA muscle of 4.5-month-old wild-type and TWEAK-KO mice 


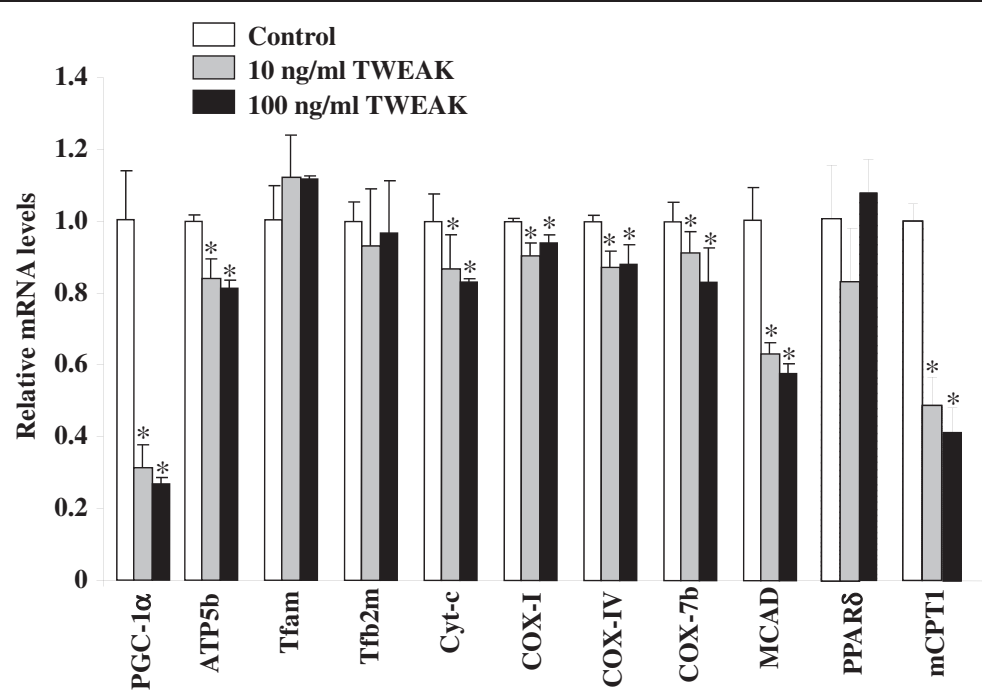

Figure 6 Effect of TWEAK on expression of PGC-1a and mitochondria oxidative metabolism genes in cultured primary myotubes. Primary myotubes prepared from wild-type mice were treated with soluble TWEAK protein $(10 \mathrm{ng} / \mathrm{ml} \mathrm{or} 100 \mathrm{ng} / \mathrm{ml})$ for 72 hours followed by RNA isolation and performing qRT-PCR to study transcript levels of PGC-1a, Tfam, Tfam2m, Cyt-c, Cox I, Cox IV, Cox 7b, and MCAD. Data are presented as mean \pm SD. ${ }^{*} P<0.05$; values vary significantly from untreated myotubes. Cox, cytochroms C oxidase; Cyt C, cytochrome C; MCAD, medium-chain acyl-coenzyme A dehydrogenase; PGC-1a, PPAR coactivator 1a; PPAR, peroxisome proliferator-activated receptor; Tfam, transcription factor A mitochondrial; TWEAK, TNF-like weak inducer of apoptosis.

was isolated and immunostained with antibodies against CD31 (also known as platelet endothelial cell adhesion molecule-1), an endothelial-specific marker for capillaries. Laminin staining was used to mark the periphery of fibers. As shown in Figure 8A, the number of CD31positive capillaries was considerably increased in TWEAKKO mice compared with wild-type mice. The capillaryto-fiber ratio was increased by $29 \%$ in TWEAK-KO mice (Figure 8B). Since VEGF positively regulates angiogenesis, we also measured mRNA levels of VEGF in TA muscle of wild-type and TWEAK-KO mice. As shown in Figure 8C, mRNA levels of VEGF were significantly higher in TA muscle of TWEAK-KO mice compared to wild-type mice. Furthermore, treatment with TWEAK also reduced the mRNA levels of VEGF in primary myotubes (Figure 8D). These results suggest that ablation of TWEAK stimulates angiogenesis in skeletal muscle of mice potentially through increasing the expression of VEGF.

\section{Discussion}

Exercise capacity in mammals is determined by multiple factors including skeletal muscle oxidative metabolism and vascularization. Our previous microarray study suggested that TWEAK can modulate the expression of several genes whose products are involved in mitochondrial dysfunction and fatty acid metabolism [53]. Our present study demonstrates that compared to wild-type mice, TWEAK-KO mice run longer and with higher speed during an exercise tolerance test (Figure 1). TWEAK$\mathrm{KO}$ mice show augmented levels of subsarcolemmal and intermyofibrillar mitochondria, increased SDH-positive myofibers, and elevated expression of metabolic genes such as PGC-1 $\alpha$, PPAR $\delta$, and mCPT- 1 compared to wildtype mice (Figures 2, 3, and 4). Oxidative phosphorylation is also increased in exercised TWEAK-KO mice compared with wild-type mice (Figure 5), and treatment of myotubes with TWEAK directly decreases mitochondrial biogenetic capacity and maximal respiratory activity (Figures 6 and 7). Moreover, vascularization and expression of VEGF in skeletal muscle are enhanced in TWEAK-KO mice compared to their controls (Figure 8). These data suggest that TWEAK directly regulates the mitochondrial biogenetic program and that loss of TWEAK improves mitochondrial respiratory capacity and increases vascularization of skeletal muscle tissue, which collectively lead to improved exercise performance.

One of the potential mechanisms by which TWEAK might be attenuating exercise capacity is through diminishing the levels of PGC- $1 \alpha$ in skeletal muscle. PGC- $1 \alpha$ augments mitochondrial biogenesis, oxidative metabolism, and promotes fast-to-slow type fiber transition $[9,13,17,54-56]$. Overexpression of PGC-1 $\alpha$ in rat primary culture cells leads to increased abundance of slow oxidative-associated MyHC isoform [57]. Skeletal muscle-specific PGC-1 $\alpha$ KO mice demonstrate reduced endurance capacity with a shift from oxidative fiber type to glycolytic fibers and increased levels of TNF- $\alpha$ in skeletal muscle [45,58]. By contrast, muscle-specific overexpression of PGC- $1 \alpha$ enhances exercise performance with increased fatty acid oxidation and decreased 


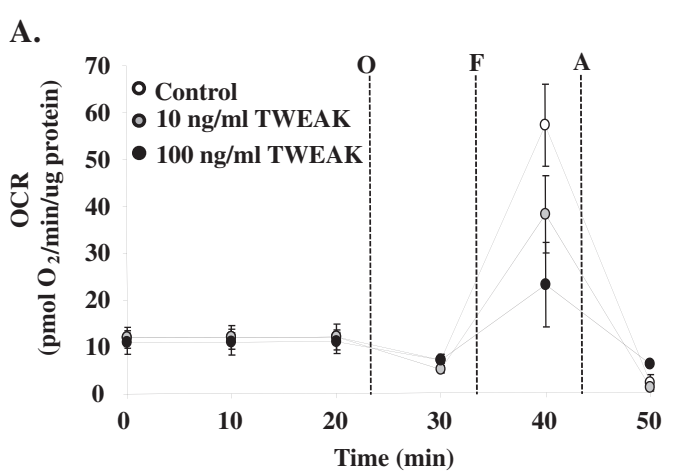

B.

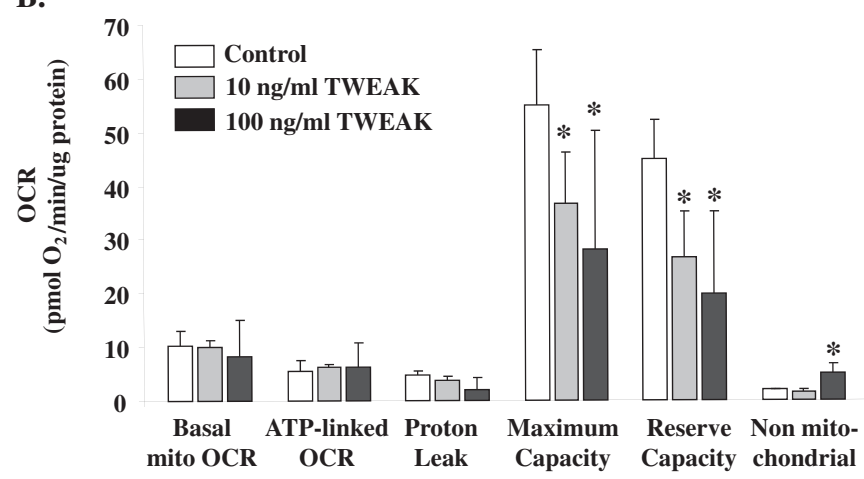

C.

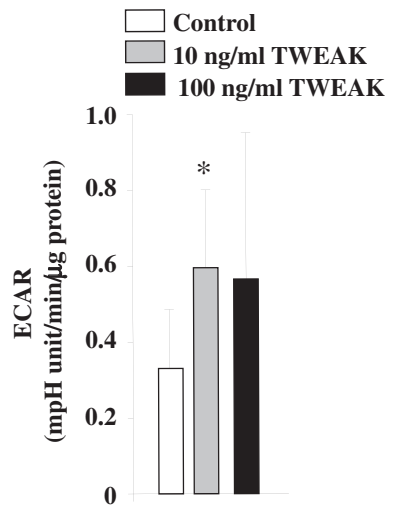

Figure 7 TWEAK regulates mitochondrial oxidative capacity and glycolytic flux. Extracellular flux analysis of primary differentiated myotubes treated with 0,10 , or $100 \mathrm{ng} / \mathrm{ml}$ TWEAK for 72 hours. (A) Mitochondrial function assay: after three baseline measurements, inhibitors or activators of electron transport were added sequentially to intact myotubes. Oxygen consumption rate (OCR) measurements were recorded after each exposure. O, oligomycin; F, FCCP; and A, antimycin A/rotenone. The OCR was normalized to total protein in each well. (B) Indices of mitochondrial function calculated from assay results in panel A. (C) Extracellular acidification rates (ECAR) of cells treated without or with TWEAK; ECAR is a surrogate measure of lactate and therefore is used as a measure of glycolytic flux. $\mathrm{N}=3$ per group; ${ }^{*} P<0.05$ versus control. FCCP, carbonyl cyanide $p$-trifluoromethoxyphenylhydrazone; TWEAK, TNF-like weak inducer of apoptosis.

glycogen usage during exercise [8,52]. These findings suggest that PGC- $1 \alpha$ is not only essential but sufficient to determining skeletal muscle fiber composition. Our experiments demonstrate that mRNA levels of PGC- $1 \alpha$ are increased in skeletal muscle of TWEAK-KO mice with a concomitant increase in mitochondrial content and expression of genes whose products are involved in oxidative capacity (Figures 2 and 4). Furthermore, treatment of primary myotubes with TWEAK drastically reduced levels of PGC-1 $\alpha$ and other mitochondrial genes (Figure 6) further suggesting that TWEAK represses the expression of PGC- $1 \alpha$ leading to reduced mitochondrial content. These findings are consistent with functional analyses of mitochondrial function: ablation of TWEAK resulted in increased oxidative phosphorylation capacity in isolated mitochondria (Figure 5) and treatment of myotubes with TWEAK decreased maximal respiratory capacity (Figure 7). Although not tested in this study, it is possible that TWEAK also reduces the levels of PGC$1 \alpha$ in other organs which ultimately results in reduced exercise capacity. Indeed, Shi et al. recently reported that TWEAK represses the expression of PGC- $1 \alpha$ and other molecules involved in mitochondrial oxidative phosphorylation in cardiomyocytes and forced expression of PGC- $1 \alpha$ attenuates TWEAK-induced cardiac dysfunction in mice [59].

The PPARs are ligand-modulated transcription factors in which three subtypes have been identified: $\alpha, \beta / \delta$, and $\gamma$ [60]. Previous studies have shown that their endogenous ligands are composed of fatty acids and lipid metabolites and, therefore, certain PPARs mediate the expression of genes whose products are involved in the regulation of fatty acid metabolism in response to changes in systemic fuel availability [60-62]. In skeletal muscle, levels of PPAR $\delta$ are relatively higher compared to PPARa or PPARy [63]. Treatment with synthetic PPAR $\delta$ agonist or overexpression of PPAR $\delta$ by retroviral infection induces the levels of molecules which are involved in lipid metabolism and fatty acid oxidation, whereas overexpression of a dominant-negative PPAR $\delta$ mutant exerts opposite effects in $\mathrm{C} 2 \mathrm{C} 12$ myotubes [64]. Furthermore, it has been shown that muscle-specific overexpression of PPAR $\delta$ in mice increases exercise tolerance with a switch to increased number of type I 


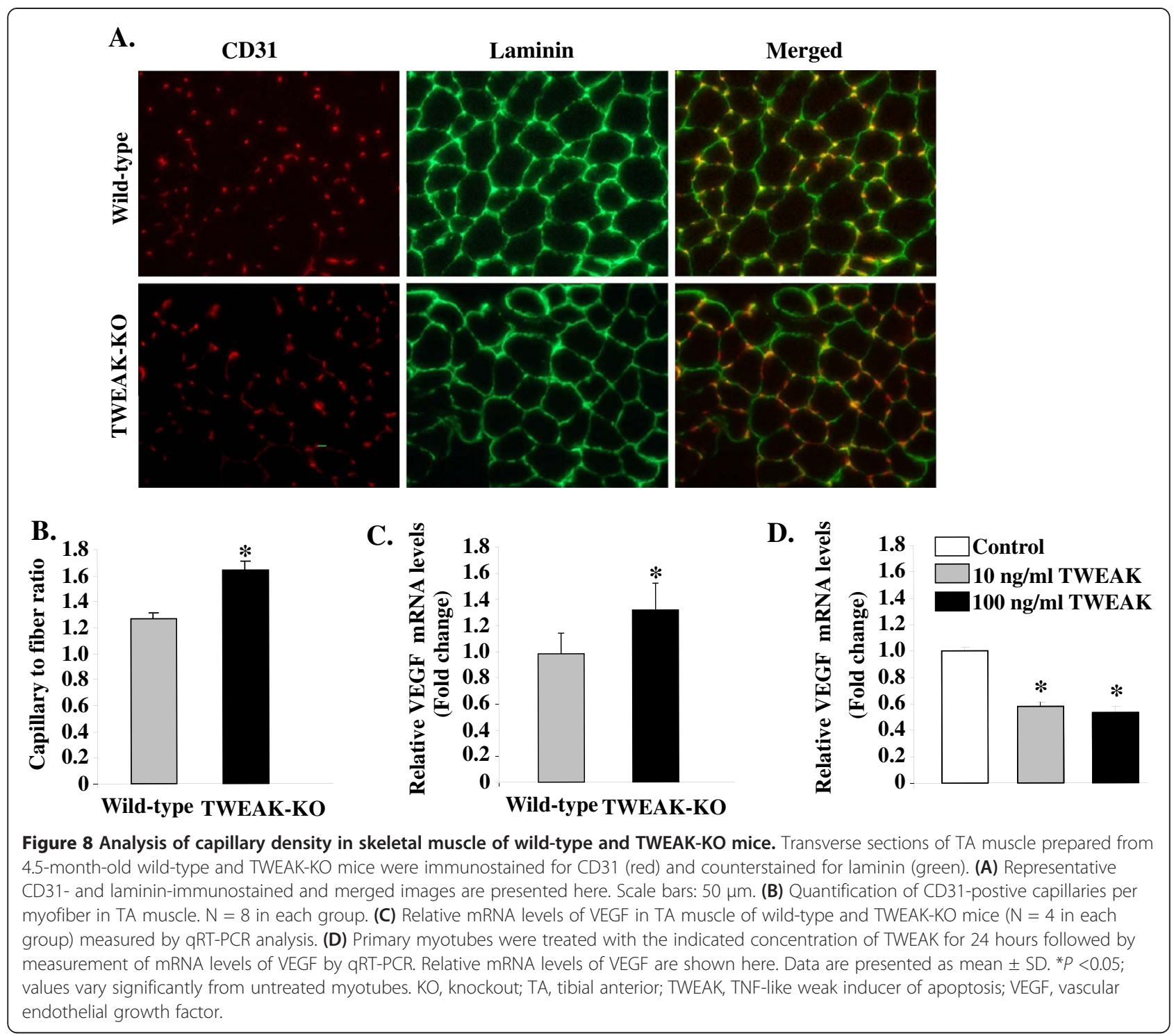

muscle fibers and up-regulation of molecules related to fatty acid metabolism. In contrast, PPAR $\delta$-null mice show decreased exercise performance compared to wildtype mice $[65,66]$. Although muscle relies mainly on fat and carbohydrate as energy resources, enhanced fatty acid utilization during exercise with glycogen sparing results in improved exercise endurance capacity [67-69]. Haramizu et al. demonstrated that the expression levels of gene products related to lipid metabolism in the muscle is correlated with the levels of fatty acid $\beta$ oxidation activity as well as exercise strength [70]. Our results demonstrate that transcript levels of PPAR $\delta$ and mCPT1 are significantly increased while the expression of molecules that are associated with glycolysis such as HK II and PGAM2 is suppressed in skeletal muscle of TWEAK-KO mice compared to wild-type mice (Figure 6). These results suggest that enhanced fatty acid oxidation might be responsible for improvement in exercise capacity in TWEAK-KO mice. Data from cell culture experiments further support this possibility, as treatment of myotubes with TWEAK resulted in diminished maximal respiratory capacity and increased glycolytic flux (Figure 7).

Although the mechanisms by which TWEAK reduces levels of PGC-1 $\alpha$ in skeletal muscle remain unknown, a recent study has shown that TWEAK increases membrane translocation of adaptor protein TNF receptor associated factor 2 (TRAF2), in an Fn14 dependent manner, in cardiomyocytes [59]. Furthermore, TWEAK treatment increases the activation of canonical nuclear factor-kappaB (NF-kB) signaling in both skeletal muscle [41] and cardiac myocytes [59]. Knockdown of TRAF2 using small hairpin RNA (shRNA) or selective blockade of ІкB kinase- $\beta$ (IKK $\beta$, an upstream activator of canonical NF- $\mathrm{KB}$ signaling) prevented the TWEAK-mediated suppression of 
PGC-1 $\alpha$ in cardiomyocytes suggesting that TWEAK repression of PGC-1 $\alpha$ requires Fn14-TRAF2-IKK $\beta$-NF- $\mathrm{kB}$ signaling cascade [59]. Previously, the effects of TNF- $\alpha$ on the mRNA expression of PPAR $\delta$ and its target genes have been investigated. Treatment with TNF- $\alpha$ reduces PPAR $\delta$-target genes, such as mCPT1 and PGC- $1 \alpha$, whereas addition of PPAR $\delta$ agonist rescues this reduction in adipocytes [71,72]. Moreover, TNF- $\alpha$ impairs mitochondrial biogenesis and function in skeletal muscle [73]. While TWEAK can induce the expression of molecules associated with the autophagy-lysosomal system indicating it causes mitochondria dysfunction [74], muscle-specific ablation of TRAF6, which is involved in TWEAK signaling, suppresses the activation of autophagy in response to denervation and cancer cachexia [75]. These results suggest that TWEAK is involved in reducing PPAR $\delta$ and PGC- $1 \alpha$ levels and their target genes leading to mitochondrial dysfunction and content. Since no change of PPAR $\delta$ expression was observed in skeletal muscle of PGC- $1 \alpha \mathrm{KO}$ mice or the muscle-specific PGC-1 $\alpha$ overexpressing transgenic mice [66], PGC- $1 \alpha$ is not an upstream regulator for PPAR $\delta$. Indeed, PGC- $1 \alpha$ has a synergistic effect with PPAR $\delta$ agonist to induce the expression of oxidative metabolic genes such as $m C P T 1$ and PDK4 [76]. Furthermore, it has been shown that PGC- $1 \alpha$ directly coactivates the $m C P T 1$ and PDK4 promoter via PPAR $\delta$ in a liganddependent manner $[76,77]$. Therefore, it is likely that PGC- $1 \alpha$ is a coactivator of PPAR $\delta$ in terms of upregulating these metabolic genes.

Another interesting observation of the present study is that depletion of TWEAK improves angiogenesis in skeletal muscle of mice (Figure 8). Previous studies have shown that transgenic mice overexpressing PGC-1 $\alpha$ show increased vascularization in skeletal muscle [56]. PGC-1 $\alpha$ is also a positive regulator for the expression of VEGF1 which is known to promote angiogenesis [56]. Moreover, human endothelial cells treated with the PPAR $\delta$ agonist GW501516 demonstrated increased production of VEGF and expression of VEGF receptor [78,79]. Therefore, increased angiogenesis in skeletal muscle of TWEAK-KO mice appears to be a result of increased amounts of PGC- $1 \alpha$ and PPAR $\delta$ (Figure 4). The enhancement of vascularization in TWEAK-KO mice might further augment the capacity of skeletal muscle mitochondria to respire by increasing blood flow and delivery of $\mathrm{O}_{2}$ and nutrients, especially during exercise.

\section{Conclusion}

In summary, our study provides initial evidence that inhibition of TWEAK increases mitochondrial biogenesis, oxidative metabolism and angiogenesis in skeletal muscle which potentially contribute to improved exercise capacity. These findings also have high clinical significance as inhibition of TWEAK activity using neutralizing antibodies or pharmacological compounds could improve muscle function and exercise capacity in patients with metabolic disorders.

\section{Abbreviations}

ATP5b: ATP synthase subunit beta; BSA: Bovine serum albumin; Cox: Cytochrome c oxidase; FCCP: Carbonyl cyanide $p$-trifluoromethoxyphenylhydrazone; GA: Gastrocnemius; HK II: Hexokinase Il; KO: Knockout; MCAD: Medium-chain acyl-coenzyme A dehydrogenase; mCPT1: Mitochondrial carnitine palmitoyltransferase I; MyHC: Myosin heavy chain; NF-KB: Nuclear factor-kappaB; OCR: Oxygen consumption rate; PCR: Polymerase chain reaction; PDK4: Pyruvate dehydrogenase kinase 4; PGAM2: Phosphoglycerate mutase 2; PGC-1 a: PPAR coactivator 1a; PPAR: Peroxisome proliferator-activated receptor; qRTPCR: Quantitative real-time PCR; SDH: Succinate dehydrogenase; shRNA: Small hairpin RNA; TA: Tibial anterior; TNF: Tumor necrosis factor; TRAF: TNF receptorassociated factor; TWEAK:TNF-like weak inducer of apoptosis; VEGF: Vascular endothelial growth factor.

\section{Competing interests}

The authors declare they have no competing interests.

\section{Authors' contributions}

AK and BGH conceived and designed the study. SS, YO, VM, JS, BGH and SB performed experiments and analyzed the data. SS, BGH and AK wrote the manuscript. All authors read and approved the final manuscript.

\section{Acknowledgements}

We are grateful to Dr. Avi Ashkenazi (Genentech South San Francisco, CA) for providing TWEAK-KO mice. This work was supported by NIH grants R01AR059810 and RO1AG029623 to AK.

\section{Author details}

'Department of Anatomical Sciences and Neurobiology, University of Louisville School of Medicine, 500 South Preston Street, Louisville, KY 40202, USA.

${ }^{2}$ Diabetes and Obesity Center, Institute of Molecular Cardiology, and Department of Medicine, University of Louisville, Louisville, KY 40202, USA

${ }^{3}$ Present address: Gastroenterology Division, University of Pittsburgh School of Medicine, Pittsburgh, PA 15261, USA.

Received: 3 April 2013 Accepted: 9 May 2013

Published: 8 July 2013

\section{References}

1. Pette D: The adaptive potential of skeletal muscle fibers. Can J Appl Physiol 2002, 27:423-448

2. Holloszy JO: Biochemical adaptations in muscle. Effects of exercise on mitochondrial oxygen uptake and respiratory enzyme activity in skeletal muscle. J Biol Chem 1967, 242:2278-2282.

3. Lanza IR, Sreekumaran Nair K: Regulation of skeletal muscle mitochondrial function: genes to proteins. Acta Physiol (Oxf) 2010, 199:529-547.

4. Arany Z: PGC-1 coactivators and skeletal muscle adaptations in health and disease. Curr Opin Genet Dev 2008, 18:426-434.

5. Finck BN, Kelly DP: PGC-1 coactivators: inducible regulators of energy metabolism in health and disease. J Clin Invest 2006, 116:615-622.

6. Uldry M, Yang W, St-Pierre J, Lin J, Seale P, Spiegelman BM: Complementary action of the PGC-1 coactivators in mitochondrial biogenesis and brown fat differentiation. Cell Metab 2006, 3:333-341.

7. Arany Z, Lebrasseur N, Morris C, Smith E, Yang W, Ma Y, Chin S, Spiegelman BM: The transcriptional coactivator PGC-1beta drives the formation of oxidative type IIX fibers in skeletal muscle. Cell Metab 2007, 5:35-46.

8. Calvo JA, Daniels TG, Wang X, Paul A, Lin J, Spiegelman BM, Stevenson SC, Rangwala SM: Muscle-specific expression of PPARgamma coactivator-1alpha improves exercise performance and increases peak oxygen uptake. J Appl Physiol 2008, 104:1304-1312.

9. Lin J, Wu H, Tarr PT, Zhang CY, Wu Z, Boss O, Michael LF, Puigserver P, Isotani E, Olson EN, Lowell BB, Bassel-Duby R, Spiegelman BM: Transcriptional co-activator PGC-1 alpha drives the formation of slow-twitch muscle fibres. Nature 2002, 418:797-801. 
10. Wende AR, Schaeffer PJ, Parker GJ, Zechner C, Han DH, Chen MM, Hancock CR, Lehman JJ, Huss JM, McClain DA, Holloszy JO, Kelly DP: A role for the transcriptional coactivator PGC-1alpha in muscle refueling. J Biol Chem 2007, 282:36642-36651.

11. Sandri M, Lin J, Handschin C, Yang W, Arany ZP, Lecker SH, Goldberg AL, Spiegelman BM: PGC-1alpha protects skeletal muscle from atrophy by suppressing $\mathrm{FoxO} 3$ action and atrophy-specific gene transcription. Proc Natl Acad Sci U S A 2006, 103:16260-16265.

12. Brault JJ, Jespersen JG, Goldberg AL: Peroxisome proliferator-activated receptor gamma coactivator 1alpha or 1beta overexpression inhibits muscle protein degradation, induction of ubiquitin ligases, and disuse atrophy. J Biol Chem 2010, 285:19460-19471.

13. Wu Z, Puigserver P, Andersson U, Zhang C, Adelmant G, Mootha V, Troy A, Cinti S, Lowell B, Scarpulla RC, Spiegelman BM: Mechanisms controlling mitochondrial biogenesis and respiration through the thermogenic coactivator PGC-1. Cell 1999, 98:115-124.

14. Mootha VK, Handschin C, Arlow D, Xie X, St Pierre J, Sihag S, Yang W, Altshuler D, Puigserver P, Patterson N, Willy PJ, Schulman IG, Heyman RA, Lander ES, Spiegelman BM: Erralpha and Gabpa/b specify PGC-1alpha-dependent oxidative phosphorylation gene expression that is altered in diabetic muscle. Proc Natl Acad Sci USA 2004, 101:6570-6575.

15. Huss JM, Kopp RP, Kelly DP: Peroxisome proliferator-activated receptor coactivator-1alpha (PGC-1alpha) coactivates the cardiac-enriched nuclear receptors estrogen-related receptor-alpha and-gamma. Identification of novel leucine-rich interaction motif within PGC-1alpha. J Biol Chem 2002, 277:40265-40274.

16. Huss JM, Torra IP, Staels B, Giguere V, Kelly DP: Estrogen-related receptor alpha directs peroxisome proliferator-activated receptor alpha signaling in the transcriptional control of energy metabolism in cardiac and skeletal muscle. Mol Cell Biol 2004, 24:9079-9091.

17. Puigserver $P$, Wu Z, Park CW, Graves R, Wright M, Spiegelman BM: A cold-inducible coactivator of nuclear receptors linked to adaptive thermogenesis. Cell 1998, 92:829-839.

18. Scarpulla RC: Transcriptional paradigms in mammalian mitochondrial biogenesis and function. Physiol Rev 2008, 88:611-638.

19. Romanello V, Guadagnin E, Gomes L, Roder I, Sandri C, Petersen Y, Milan G, Masiero E, Del Piccolo P, Foretz M, Scorrano L, Rudolf R, Sandri M: Mitochondrial fission and remodelling contributes to muscle atrophy. EMBO J 2010, 29:1774-1785.

20. Lokireddy S, Wijesoma IW, Teng S, Bonala S, Gluckman PD, McFarlane C, Sharma M, Kambadur R: The ubiquitin ligase Mul1 induces mitophagy in skeletal muscle in response to muscle-wasting stimuli. Cell Metab 2012, 16:613-624.

21. Argiles JM, Busquets S, Toledo M, Lopez-Soriano FJ: The role of cytokines in cancer cachexia. Curr Opin Support Palliat Care 2009, 3:263-268.

22. Carson JA, Baltgalvis KA: Interleukin 6 as a key regulator of muscle mass during cachexia. Exerc Sport Sci Rev 2010, 38:168-176.

23. Hardin BJ, Campbell KS, Smith JD, Arbogast S, Smith J, Moylan JS, Reid MB: TNF-alpha acts via TNFR1 and muscle-derived oxidants to depress myofibrillar force in murine skeletal muscle. J Appl Physiol 2008, 104:694-699.

24. Reid MB, Lannergren J, Westerblad H: Respiratory and limb muscle weakness induced by tumor necrosis factor-alpha: involvement of muscle myofilaments. Am J Respir Crit Care Med 2002, 166:479-484.

25. Li YP, Schwartz RJ, Waddell ID, Holloway BR, Reid MB: Skeletal muscle myocytes undergo protein loss and reactive oxygen-mediated NF-kappaB activation in response to tumor necrosis factor alpha. FASEB J 1998, 12:871-880.

26. Li YP, Reid MB: NF-kappaB mediates the protein loss induced by TNF-alpha in differentiated skeletal muscle myotubes. Am J Physiol Regul Integr Comp Physiol 2000, 279:R1165-R1170.

27. Reid MB, Moylan JS: Beyond atrophy: redox mechanisms of muscle dysfunction in chronic inflammatory disease. J Physiol 2011, 589:2171-2179.

28. Romanatto T, Roman EA, Arruda AP, Denis RG, Solon C, Milanski M, Moraes JC, Bonfleur ML, Degasperi GR, Picardi PK, Hirabara S, Boschero AC, Curi R, Velloso LA: Deletion of tumor necrosis factor-alpha receptor 1 (TNFR1) protects against diet-induced obesity by means of increased thermogenesis. J Biol Chem 2009, 284:36213-36222.

29. Tang K, Wagner PD, Breen EC: TNF-alpha-mediated reduction in PGC-1alpha may impair skeletal muscle function after cigarette smoke exposure. J Cell Physiol 2010, 222:320-327.
30. White JP, Puppa MJ, Sato S, Gao S, Price RL, Baynes JW, Kostek MC, Matesic LE, Carson JA: IL-6 regulation on skeletal muscle mitochondrial remodeling during cancer cachexia in the ApcMin/+ mouse. Skelet Muscle 2012, 2:14.

31. White JP, Baltgalvis KA, Puppa MJ, Sato S, Baynes JW, Carson JA: Muscle oxidative capacity during IL-6-dependent cancer cachexia. Am J Physiol Regul Integr Comp Physiol 2011, 300:R201-R211.

32. Mangner N, Linke A, Oberbach A, Kullnick Y, Gielen S, Sandri M, Hoellriegel R, Matsumoto Y, Schuler G, Adams V: Exercise training prevents TNF-alpha induced loss of force in the diaphragm of mice. PLOS One 2013, 8:e52274.

33. Santos RV, Viana VA, Boscolo RA, Marques VG, Santana MG, Lira FS, Tufik S, de Mello MT: Moderate exercise training modulates cytokine profile and sleep in elderly people. Cytokine 2012, 60:731-735.

34. Rubin DA, Hackney AC: Inflammatory cytokines and metabolic risk factors during growth and maturation: influence of physical activity. Med Sport Sci 2010, 55:43-55.

35. Christiansen T, Bruun JM, Paulsen SK, Olholm J, Overgaard K, Pedersen SB, Richelsen B: Acute exercise increases circulating inflammatory markers in overweight and obese compared with lean subjects. Eur J Appl Physiol 2013, 113:1635-1642.

36. Chicheportiche Y, Bourdon PR, Xu H, Hsu YM, Scott H, Hession C, Garcia I, Browning JL: TWEAK, a new secreted ligand in the tumor necrosis factor family that weakly induces apoptosis. J Biol Chem 1997, 272:32401-32410.

37. Meighan-Mantha RL, Hsu DK, Guo Y, Brown SA, Feng SL, Peifley KA, Alberts GF, Copeland NG, Gilbert DJ, Jenkins NA, Richards CM, Winkles JA: The mitogen-inducible Fn14 gene encodes a type I transmembrane protein that modulates fibroblast adhesion and migration. J Biol Chem 1999, 274:33166-33176.

38. Winkles JA, Tran NL, Brown SA, Stains N, Cunliffe HE, Berens ME: Role of TWEAK and Fn14 in tumor biology. Front Biosci 2007, 12:2761-2771.

39. Wiley SR, Cassiano L, Lofton T, Davis-Smith T, Winkles JA, Lindner V, Liu H, Daniel TO, Smith CA, Fanslow WC: A novel TNF receptor family member binds TWEAK and is implicated in angiogenesis. Immunity 2001, 15:837-846.

40. Maecker $H$, Varfolomeev $E_{1}$ Kischkel $F$, Lawrence D, LeBlanc $H$, Lee W, Hurst S, Danilenko D, Li J, Filvaroff E, Yang B, Daniel D, Ashkenazi A: TWEAK attenuates the transition from innate to adaptive immunity. Cell 2005 123:931-944.

41. Mittal A, Bhatnagar S, Kumar A, Lach-Trifilieff E, Wauters S, Li H, Makonchuk DY, Glass DJ, Kumar A: The TWEAK-Fn14 system is a critical regulator of denervation-induced skeletal muscle atrophy in mice. J Cell Biol 2010, 188:833-849.

42. Kumar A, Bhatnagar S, Paul PK: TWEAK and TRAF6 regulate skeletal muscle atrophy. Curr Opin Clin Nutr Metab Care 2012, 15:233-239.

43. Dahiya S, Bhatnagar S, Hindi SM, Jiang C, Paul PK, Kuang S, Kumar A Elevated levels of active matrix metalloproteinase- 9 cause hypertrophy in skeletal muscle of normal and dystrophin-deficient mdx mice. Hum Mol Genet 2011, 20:4345-4359.

44. Safdar A, Little JP, Stokl AJ, Hettinga BP, Akhtar M, Tarnopolsky MA: Exercise increases mitochondrial PGC-1alpha content and promotes nuclear-mitochondrial cross-talk to coordinate mitochondrial biogenesis. J Biol Chem 2011, 286:10605-10617

45. Handschin C, Chin S, Li P, Liu F, Maratos-Flier E, Lebrasseur NK, Yan Z, Spiegelman BM: Skeletal muscle fiber-type switching, exercise intolerance, and myopathy in PGC-1alpha muscle-specific knock-out animals. J Biol Chem 2007, 282:30014-30021.

46. Nachlas MM, Tsou KC, De Souza E, Cheng CS, Seligman AM: Cytochemical demonstration of succinic dehydrogenase by the use of a new $\mathrm{p}$ nitrophenyl substituted ditetrazole. J Histochem Cytochem 1957, 5:420-436.

47. Sauerbeck A, Pandya J, Singh I, Bittman K, Readnower R, Bing G, Sullivan P. Analysis of regional brain mitochondrial bioenergetics and susceptibility to mitochondrial inhibition utilizing a microplate based system. J Neurosci Methods 2011, 198:36-43.

48. Hill BG, Dranka BP, Zou L, Chatham JC, Darley-Usmar VM: Importance of the bioenergetic reserve capacity in response to cardiomyocyte stress induced by 4-hydroxynonenal. Biochem J 2009, 424:99-107.

49. Dranka BP, Hill BG, Darley-Usmar VM: Mitochondrial reserve capacity in endothelial cells: the impact of nitric oxide and reactive oxygen species. Free Radic Biol Med 2010, 48:905-914.

50. Perez J, Hill BG, Benavides GA, Dranka BP, Darley-Usmar VM: Role of cellular bioenergetics in smooth muscle cell proliferation induced by platelet-derived growth factor. Biochem J 2010, 428:255-267. 
51. Hill BG, Benavides GA, Lancaster JR, Ballinger S, Dell'italia L, Zhang J, Darley-Usmar VM: Integration of cellular bioenergetics with mitochondrial quality control and autophagy. Biol Chem 2012, 393:1485-1512.

52. Tadaishi M, Miura S, Kai Y, Kano Y, Oishi Y, Ezaki O: Skeletal muscle-specific expression of PGC-1alpha-b, an exercise-responsive isoform, increases exercise capacity and peak oxygen uptake. PLoS One 2011, 6:e28290.

53. Panguluri SK, Bhatnagar S, Kumar A, McCarthy JJ, Srivastava AK, Cooper NG, Lundy RF: Genomic profiling of messenger RNAs and microRNAs reveals potential mechanisms of TWEAK-induced skeletal muscle wasting in mice. PLoS One 2010, 5:e8760.

54. Vega RB, Huss JM, Kelly DP: The coactivator PGC-1 cooperates with peroxisome proliferator-activated receptor alpha in transcriptional control of nuclear genes encoding mitochondrial fatty acid oxidation enzymes. Mol Cell Biol 2000, 20:1868-1876.

55. Liang H, Ward WF: PGC-1alpha: a key regulator of energy metabolism. Adv Physiol Educ 2006, 30:145-151.

56. Chinsomboon J, Ruas J, Gupta RK, Thom R, Shoag J, Rowe GC, Sawada N, Raghuram S, Arany Z: The transcriptional coactivator PGC-1alpha mediates exercise-induced angiogenesis in skeletal muscle. Proc Natl Acad Sci U S A 2009, 106:21401-21406.

57. Mortensen $\mathrm{OH}$, Frandsen $\mathrm{L}$, Schjerling $\mathrm{P}$, Nishimura $\mathrm{E}$, Grunnet N: PGC-1alpha and PGC-1 beta have both similar and distinct effects on myofiber switching toward an oxidative phenotype. Am J Physiol Endocrinol Metab 2006, 291:E807-E816.

58. Leone TC, Lehman JJ, Finck BN, Schaeffer PJ, Wende AR, Boudina S, Courtois M, Wozniak DF, Sambandam N, Bernal-Mizrachi C, Chen Z, Holloszy JO, Medeiros DM, Schmidt RE, Saffitz JE, Abel ED, Semenkovich CF, Kelly DP: PGC-1alpha deficiency causes multi-system energy metabolic derangements: muscle dysfunction, abnormal weight control and hepatic steatosis. PLoS Biol 2005, 3:e101.

59. Shi J, Jiang B, Qiu Y, Guan J, Jain M, Cao X, Bauer M, Su L, Burkly LC, Leone TC, Kelly DP, Liao R: PGC1alpha plays a critical role in TWEAK-induced cardiac dysfunction. PLOS One 2013, 8:e54054

60. Kliewer SA, Xu HE, Lambert MH, Willson TM: Peroxisome proliferatoractivated receptors: from genes to physiology. Recent Prog Horm Res 2001, 56:239-263.

61. Takahashi S, Tanaka T, Sakai J: New therapeutic target for metabolic syndrome: PPARdelta. Endocr J 2007, 54:347-357.

62. Fredenrich A, Grimaldi PA: PPAR delta: an uncompletely known nuclear receptor. Diabetes Metab 2005, 31:23-27.

63. Muoio DM, MacLean PS, Lang DB, Li S, Houmard JA, Way JM, Winegar DA, Corton JC, Dohm GL, Kraus WE: Fatty acid homeostasis and induction of lipid regulatory genes in skeletal muscles of peroxisome proliferatoractivated receptor (PPAR) alpha knock-out mice. Evidence for compensatory regulation by PPAR delta. J Biol Chem 2002, 277:26089-26097.

64. Holst D, Luquet S, Nogueira V, Kristiansen K, Leverve X, Grimaldi PA: Nutritional regulation and role of peroxisome proliferator-activated receptor delta in fatty acid catabolism in skeletal muscle. Biochim Biophys Acta 2003, 1633:43-50.

65. Luquet S, Lopez-Soriano J, Holst D, Fredenrich A, Melki J, Rassoulzadegan M, Grimaldi PA: Peroxisome proliferator-activated receptor delta controls muscle development and oxidative capability. FASEB J 2003, 17:2299-2301.

66. Wang YX, Zhang CL, Yu RT, Cho HK, Nelson MC, Bayuga-Ocampo CR, Ham J, Kang H, Evans RM: Regulation of muscle fiber type and running endurance by PPARdelta. PLOS Biol 2004, 2:e294.

67. Hawley JA, Brouns F, Jeukendrup A: Strategies to enhance fat utilisation during exercise. Sports Med 1998, 25:241-257.

68. Helge JW: Long-term fat diet adaptation effects on performance, training capacity, and fat utilization. Med Sci Sports Exerc 2002, 34:1499-1504

69. Miller WC, Bryce GR, Conlee RK: Adaptations to a high-fat diet that increase exercise endurance in male rats. J App/ Physiol 1984, 56:78-83.

70. Haramizu S, Nagasawa A, Ota N, Hase T, Tokimitsu I, Murase T: Different contribution of muscle and liver lipid metabolism to endurance capacity and obesity susceptibility of mice. J Appl Physiol 2009, 106:871-879.

71. Rodriguez-Calvo R, Serrano L, Coll T, Moullan N, Sanchez RM, Merlos M, Palomer X, Laguna JC, Michalik L, Wahli W, Vazquez-Carrera M: Activation of peroxisome proliferator-activated receptor beta/delta inhibits lipopolysaccharide-induced cytokine production in adipocytes by lowering nuclear factor-kappaB activity via extracellular signal-related kinase 1/2. Diabetes 2008, 57:2149-2157.
72. Serrano-Marco L, Chacon MR, Maymo-Masip E, Barroso E, Salvado L, Wabitsch M, Garrido-Sanchez L, Tinahones FJ, Palomer X, Vendrell J, Vazquez-Carrera M: TNF-alpha inhibits PPARbeta/delta activity and SIRT1 expression through NF-kappaB in human adipocytes. Biochim Biophys Acta 2012, 1821:1177-1185.

73. Valerio A, Cardile A, Cozzi V, Bracale R, Tedesco L, Pisconti A, Palomba L, Cantoni O, Clementi E, Moncada S, Carruba MO, Nisoli E: TNF-alpha downregulates eNOS expression and mitochondrial biogenesis in fat and muscle of obese rodents. J Clin Invest 2006, 116:2791-2798.

74. Bhatnagar S, Mittal A, Gupta SK, Kumar A: TWEAK causes myotube atrophy through coordinated activation of ubiquitin-proteasome system, autophagy, and caspases. J Cell Physiol 2012, 227:1042-1051.

75. Paul PK, Gupta SK, Bhatnagar S, Panguluri SK, Darnay BG, Choi Y, Kumar A: Targeted ablation of TRAF6 inhibits skeletal muscle wasting in mice. J Cell Biol 2010, 191:1395-1411.

76. Kleiner S, Nguyen-Tran V, Bare O, Huang X, Spiegelman B, Wu Z: PPAR \{delta\} agonism activates fatty acid oxidation via PGC-1\{alpha\} but does not increase mitochondrial gene expression and function. J Biol Chem 2009, 284:18624-18633.

77. Dressel U, Allen TL, Pippal JB, Rohde PR, Lau P, Muscat GE: The peroxisome proliferator-activated receptor beta/delta agonist, GW501516, regulates the expression of genes involved in lipid catabolism and energy uncoupling in skeletal muscle cells. Mol Endocrinol 2003, 17:2477-2493.

78. Piqueras L, Reynolds AR, Hodivala-Dilke KM, Alfranca A, Redondo JM, Hatae T, Tanabe T, Warner TD, Bishop-Bailey D: Activation of PPARbeta/delta induces endothelial cell proliferation and angiogenesis. Arterioscler Thromb Vasc Biol 2007, 27:63-69.

79. Stephen RL, Gustafsson MC, Jarvis M, Tatoud R, Marshall BR, Knight D, Ehrenborg E, Harris AL, Wolf CR, Palmer CN: Activation of peroxisome proliferator-activated receptor delta stimulates the proliferation of human breast and prostate cancer cell lines. Cancer Res 2004, 64:3162-3170

\section{doi:10.1186/2044-5040-3-18}

Cite this article as: Sato et al:: TWEAK promotes exercise intolerance by decreasing skeletal muscle oxidative phosphorylation capacity. Skeletal Muscle 2013 3:18.

\section{Submit your next manuscript to BioMed Central and take full advantage of:}

- Convenient online submission

- Thorough peer review

- No space constraints or color figure charges

- Immediate publication on acceptance

- Inclusion in PubMed, CAS, Scopus and Google Scholar

- Research which is freely available for redistribution 